Lopez-Gonzalez, H., Guerrero-Sole, F. \& Griffiths, M.D. (2017). A content analysis of how 'normal' sports betting behaviour is represented in gambling advertising. Addiction Research and Theory, doi.org/10.1080/16066359.2017.1353082

\title{
A content analysis of how 'normal' sports betting behaviour is represented in gambling advertising
}

\begin{abstract}
The pervasiveness of sports betting marketing and advertising is arguably normalising betting behaviour among increasingly larger groups of population. In their adverts, bookmakers represent characters and situations that conventionalise betting and promote specific behaviours while ignoring others. The present study examined a sample of British and Spanish sports betting television adverts $(\mathrm{N}=135)$ from 2014 to 2016 to understand how bettors and betting are being represented. Using content analysis, 31 different variables grouped into seven broad categories were assessed, including general information about the advert, the characters and situations represented, the identification of the characters with sports, the use of online betting, the co-representation of gambling along other risky behaviours such as eating junk food and drinking alcohol, the amount of money wagered, and other variables such as the representation of free bets, humour, and celebrities. The results showed a male-dominant betting representation with no interaction between women. Typically, bettors were depicted surrounded by people but isolated in their betting, emphasizing the individual consumption practice that mobile betting promotes. In-play betting was observed in almost half of the adverts. A little empirical evidence indicates that betting while watching sport in betting adverts is associated with emotionally charged situations such as celebrations and/or alcohol drinking. Bettors were typically depicted staking small amounts of money with large potential returns, implying high risk bets. Overall, the study provides preliminary evidence in understanding the social representation of betting behaviour by bookmakers and critiques the problematic consequences of such representation from a public health perspective.
\end{abstract}




\section{Introduction}

Advertising has been frequently proposed as a motivational factor for initiating gambling, although the empirical evidence of its actual impact on gamblers' behaviour remains elusive (Binde, 2014; Parke, Harris, Parke, Rigbye, \& Blaszczynski, 2014). Early theorisations concerning the possible negative influence of gambling adverts and promotions on problem gamblers (e.g., Griffiths, 2005), have found more recent empirical confirmation in a large nationwide sample of over 6000 gamblers (Hanss, Mentzoni, Griffiths, \& Pallesen, 2015). However, studies associating gambling exposure with problem gambling typically acknowledge the limitations of employing self-reported data (Gainsbury et al., 2016; Hing, Russell, Lamont, \& Vitartas, 2017). Compared to short-term effects of gambling advertising, the long-term influence is even harder to evaluate, given the increase of the lapse of time from stimulus to response, which allows more variables to explain the causation (Mela, Gupta, \& Lehmann, 1997).

However, gambling companies appear to be less sceptical regarding the existence of advertising effects. Since the legalisation of online gambling in most European jurisdictions, gambling advertising expenditure has greatly increased (Van Rompuy \& Asser Institute, 2015), with some territories such as the UK reporting a $46 \%$ growth in gambling advertising from 2012 to 2015 (Davies, 2016). With regards to types of activity to gamble on, sports betting promotions are arguably one of the most pervasive forms of gambling advertising (Sproston, Hanley, Brook, Hing, \& Gainsbury, 2015). Examples include adverts embedded in match commentary, electronic banners around the playing field, commercial breaks on radio and television, official team partnerships (prominently in team shirt sponsorships), and stadium naming rights. Additionally, gambling advertising is delivered by numerous social media influencers (among them, sports journalists), and tipsters. Consequently, sports betting advertising appears to be inextricably associated with the appreciation and consumption of sport itself (Hing, Lamont, Vitartas, \& Fink, 2015; Lamont, Hing, \& Vitartas, 2016; LopezGonzalez \& Griffiths, 2016; Lopez-Gonzalez \& Tulloch, 2015; Milner, Hing, Vitartas, \& Lamont, 2013).

The mid- to long-term cumulative effect of such a volume of sports betting advertising is arguably its capacity to normalise betting behaviour (Deans, Thomas, Daube, Derevensky, \& Gordon, 2016; Deans, Thomas, Derevensky, \& Daube, 2017; Lamont, Hing, \& Gainsbury, 2011; Woolley, 2003; Reith \& Dobbie, 2011). The normalisation of betting practices due to the rise of betting marketing has (the 'has' relates to normalisation rather than the betting 
practices) prompted sport fans in interview studies to describe the betting market as 'saturated' (Thomas, Lewis, McLeod, \& Haycock, 2012), as well as seeing themselves as 'desensitised' by the continued exposure (Deans et al., 2017). One study found that an Australian watching sport on television was exposed on average to 107 gambling stimuli, including multiple formats, per game (Lindsay et al., 2013). Similar studies in Australia have found that spectators received between 10 and 15 minutes of gambling promotions every game (Gordon \& Chapman, 2014). Foreseeing this trend, McMullan and Miller coined the term gamblification of sports to refer to the increasing colonisation of sport culture by gambling operators (McMullan \& Miller, 2008).

This bombardment of advertising has raised concerns among parents about the exposure of it to their children (Pitt, Thomas, Bestman, Stoneham, \& Daube, 2016), particularly considering how likely small children are to recall betting brands associated with their favourite teams (Bestman, Thomas, Randle, \& Thomas, 2015). Some of the betting normalisation mechanisms utilized by adverts mentioned in previous literature include the use of celebrities (Lamont et al., 2016; Thomas et al., 2015), and the depiction of betting as a group activity. Interviews with young bettors have found that discussions with peers make them feel that betting with friends is a risk-free activity, and a socially accepted form of gambling (Deans, Thomas, Daube, \& Derevensky, 2017; Gavriel Fried, Teichman, \& Rahav, 2010). This confirms previous focus group research asserting that gambling on sport is not perceived as gambling per se by many participants, with less stigma associated with sports bettors than other types of gambler (Sproston et al., 2015).

Sports betting marketing and advertising might be even more problematic inasmuch as they might be representing situations and characters that exploit bettors' cognitive biases. Online gambling rests on the alleged virtues of technologically improved products that make gamblers overestimate their control over their gambles (Parke \& Griffiths, 2012). Betting on sport has been categorized as 'the most irrationally driving type of gambling', indicating the important role of perceived skills on irrational beliefs in gambling (Lund, 2011). More specifically, studies on gambling marketing have pointed out that bookmakers artificially generate near-miss situations (Reid, 1986), or that they encourage bettors to place bets on low probability events which bettors typically overestimate (Vaughan Williams, 1999).

However, although the overall impact of advertising on betting normalisation is widely acknowledged, little attention has been paid to the specific behaviours that such normalisation endorses. For definitional purposes, normalisation is understood here as the process of conforming (something) to a norm. This process comprises two types of norms. On the one 
hand, descriptive norms refer to 'individuals' beliefs about how widespread a particular behaviour is among their referent others' (Rimal \& Real, 2003, p. 185). On the other hand, injunctive norms refer to 'the extent to which individuals feel pressured into engaging in a behaviour' (Rimal \& Real, 2003, p. 187). In the case of sports betting marketing, adverts will normalise betting, first, simply by describing it repeatedly over time; and second, influencing bettors to conform to such descriptions. A similar definition of normalisation was also followed by Deans and colleagues (2017) in a recent study about bettors' behaviour.

It is essential to understand how these representations are construed because the audience often recognizes themselves as characters in the story (Hirschman, 1988). This was recently demonstrated in interviews with sports bettors, who reported that they considered bookmakers included such characters in the adverts as their mirror image (Deans et al., 2017). With that aim in mind, the present study seeks to understand how advertising normalises betting behaviour by means of representing bettors and betting in specific situations and conducting specific actions, while ignoring other alternative representations.

\section{Method}

\section{Approach}

This study draws on a social representations theoretical framework (Moscovici, 1961). In its simplest form, Moscovici's theory posits that socially shared representations serve a dual purpose. Firstly, they conventionalise (i.e., normalise) objects, individuals, and events, by giving them a definite form via their repetition in multiple contexts of social representations. Secondly, they prescribe to those exposed to such social representations, specific sets of actions and behaviours that align well with the way those objects, individuals, and events have been conventionally represented (Moscovici, 2000). The theory specifies that social representations affect collective cognitions, igniting socio-cognitive processes or mechanisms that gradually normalise the experiences represented. Mass media representation, and among them advertising, is arguably one of the most persuasive forms of social representations dissemination (Höijer, 2011). In the present study, a content analytic approach was favoured to reveal the advertising social representations of sports betting.

\section{Data collection}

The sample of adverts used in the present study was selected in the context of a larger study aiming at understanding the influence of sports betting marketing, via multiple platforms, on 
bettors with gambling problems. For the present study, a sample of sports betting television adverts was utilized $(\mathrm{N}=135)$. Adverts were selected from British and Spanish television because these were the two languages the authors could understand as native speakers, and based on the representativeness of La Liga and Premier League competitions in European soccer (1st and 3rd, respectively, in UEFA ranking). Given the diversity of brands in each market — with approximately 995 licensed betting brands in the UK; but only 36 bookmakers (with multiple brands each) in Spain (Dirección General de Ordenación del Juego [DGOJ], 2017; Gambling Commission, 2016) — , brands were selected according to their popularity on specialised internet forums, profit rankings in the gambling trade journal iGaming Business, and their presence as sponsors, official partners, and/or regular advertisers in sport events.

All adverts met the following criteria for inclusion: (i) the main or only sport depicted in the advert was soccer; (ii) only brands of bookmakers legally licensed to operate within these two countries were selected; (iii) the upload date of the adverts was from June 2014 to September 2016; (iv) adverts were shorter than 60 seconds. The sample only included television adverts because this fourth inclusion criterion excluded made-for-internet promotions that typically allow informal shooting or discussion-like videos including tipsters sponsoring a brand. Longer advertisements were excluded since they were unlikely to be shown on television; and (v) all of the adverts addressed online betting (i.e., betting via internet-based platforms).

In total, 135 adverts from 29 different betting brands were individually extracted, with the number of adverts per brand ranging from 1 to 19 . Two simultaneous mechanisms were employed to collect the materials. Primarily, adverts that met the inclusion criteria were downloaded from each brand's official YouTube channel. Secondarily, soccer matches from nine UEFA Champions League (BT Sports in the UK and Antena 3, in Spain), English Premier League (Sky Sports in the UK), and La Liga (Moviestar in Spain) were recorded from May to June 2016, including advert breaks before, during, and immediately after the games. All the adverts found in the nine matches were checked against those found on YouTube to see if the sample accurately represented the sports viewers' exposure to sports betting advertising in both countries. It was subsequently confirmed that every television advert had been made available online by bookmakers within a few weeks of their television broadcast.

\section{Data analysis}

Adverts were analysed in regard to their capacity to normalise sets of behaviours by repeating the description of betting in specific situations. Therefore, formal televisual attributes (e.g., 
lighting, colour, mise en scène [i.e., design aspects] composition, music, rhythm) were not examined. Each advert was analysed for 31 different dimensions that corresponded to seven pre-defined broad categories. A few of these categories were based on previously identified themes in existing literature on gambling advertising narratives, but most were novel. The seven categories were:

- Identification. This category included general information such as brand name, length of the advert, language, and year of upload.

- Characters and situations. In this category, adverts were examined regarding their capacity to represent specific character types in specific situations, while ignoring alternative representations. Items here included the number of characters performing substantial actions, the gender of the characters, the type of companionship characters had while betting, and the space and day time in which the betting action happened.

- Sports fan identification. Variables in this category revolved around how adverts identified bettors as sport fans. These included sportswear depiction, satisfaction over goals, belonging to a specific team, or goal celebration.

- Risky behaviours. In this category items explored the co-representation of gambling with other risky behaviours such as eating junk food and drinking alcohol.

- Online betting. This category included items about the portrayal of betting via online platforms (i.e., mobile betting) such as the simultaneous representation of betting while watching a game (i.e., in-play betting), the introduction of new resources and functionalities to bet online, the claims of ease of online betting, and the device used to bet.

- Wager placement. This category examined the visible wager details displayed on the screens of the devices that characters used to bet in the advert. This included stake, odds, potential return, and money actually won by the characters.

- Other variables. Items in this category had been previously identified in the literature. These included the claim of free or money-guaranteed bets (Hing, Sproston, Brook, \& Brading, 2017; Newall, 2015), the inclusion of elements of humour (Korn, Hurson, \& Reynolds, 2005; McMullan \& Miller, 2008), luxurious and glamorous life (Derevensky, Sklar, Gupta, \& Messerlian, 2010; Monaghan, Derevensky, \& Sklar, 2008; Sklar \& Derevensky, 2011), and/or the featuring of celebrities (Shead, Walsh, Taylor, Derevensky, \& Gupta, 2011; Thomas et al., 2015).

\section{Interrater reliability}


In order to minimize coder interpretation biases, the three authors participated as coders in the study. For that purpose, a sub-sample of 23 adverts from the UK was randomly generated. This sub-sample represented $17.03 \%$ of the overall sample, a proportion that is considered enough to assess inter-coder reliability in content analyses (Krippendorff, 2013). The first author developed a codebook with working definitions for each variable. After discussing and clarifying the definitions with the two other coders, each author independently coded all the 31 variables from the same sub-sample and reported back their coding to the first author. The most problematic definitions were adjusted to limit over-interpretation. After the second round of coding, interrater reliability was calculated using ReCal3, an online software designed for nominal data coding designs with three or more raters for which Cronbach's alpha is not appropriate. The mean interrater reliability using Krippendorff's alpha was 0.956 ( $\mathrm{SD}=0.06$, range from 0.78 to 1 ), much higher than the conservative 0.80 coefficient typically recommended by the author for content analysis (Krippendorff, 2013). Once the appropriateness of the codebook was established, the first author completed the analysis of the remaining adverts.

\section{Data processing}

The database was populated using IBM SPSS 23 for Mac. Given the exploratory nature of the study, and the lack of similar studies published, most statistical operations involved general descriptive data. Also, most variables - except variables from length, number of characters and bet amounts - were treated as nominal. In addition to reporting descriptive statistics, 16 different associations between variables were explored conducting Chi-squared tests. The targeted significance level $(\alpha<.05)$ was adjusted using the Bonferroni correction to offset the possibility of a type I error due to multiple comparisons. As a result, the threshold of statistical significance was set at .003 . Fisher's exact test coefficients are reported for associations with cell counts lower than five.

\section{Results}

Table 1 shows the main descriptive statistics from the analysed variables. Below is a summary of the main results, clustered by categories, as well as the results from the associations between variables hypothesised when conducting the analysis. 


\section{INSERT TABLE 1 AROUND HERE}

\section{Characters and situations}

Adverts had on average 2.31 characters as part of their narratives, with nearly two-thirds of the narratives (62.2\%) depicting three characters or more. A vast majority of these characters were males (2.24 male characters per advert). Over three-quarters of the adverts (77\%) did not include any women performing an action substantial to the narrative, with only five adverts including at least two women. Of those adverts including women, four-fifths only included one woman $(80.6 \%)$. No adverts in the sample depicted an interaction between two or more women. This contrasts to the number of adverts portraying active male characters, where $59 \%$ of the adverts showed three or more active men.

A large proportion of the characters who appeared in the adverts were betting alone (41.4\%) (i.e., without interacting with those around them, even when more people were in the same room). Only $24.4 \%$ of the adverts showed characters betting while interacting with others. Among those who were interacting when betting, most bet with who appeared to be (male) friends $(93.9 \%)$. The locations where betting happened varied greatly. Betting in the stands of a stadium $(21.5 \%)$, in a house $(20.7 \%)$, or outdoors were similarly frequent. A smaller proportion bet from home $(20.7 \%)$, and among these, the living room was the preferred location (78.5\%). Betting occurred more often during daytime hours $(51.1 \%)$ than night-time $(21.5 \%)$.

\section{Sports identification}

A small proportion of characters wore sportswear that identified them as sports fans $(10.4 \%)$. Around one-quarter of the adverts depicted characters showing satisfaction from the outcome of a bet or a game $(25.9 \%)$, or celebrating a goal $(25.9 \%)$. Around one-sixth of the adverts (16.3\%) explicitly marked the fact that the character had a sentimental bond with a national or professional soccer team. On aggregate, adverts with goal celebrations or bet/game celebration accounted for $37 \%$ of the sample. The possibility was explored that adverts with sports identification elements would be more likely associated with less planned behaviour, especially free bets inducements and alcohol consumption. However, no association was found between free bets and sports identification. The relationship between alcohol and sports identification is explored below.

\section{Risky behaviour}


No significant relationship was found between adverts portraying alcohol and junk food consumption. A small proportion of adverts $(8.1 \%)$ showed both alcohol and junk food consumption simultaneously. Alcohol consumption was hypothesised to be associated with emotional behaviours such as those related to sport identification. A number of those associations showed unexpected cell counts, suggesting a positive relationship between alcohol representation and (i) showing satisfaction for the outcome of a bet/game $\left(\chi^{2}[2, \mathrm{~N}=135]=6.603\right.$, $p<.037)$; (ii) celebrating a goal $\left(\chi^{2}[1, \mathrm{~N}=135]=3.978, p<.042\right)$; (iii) showing a sentimental identification with the team $\left(\chi^{2}[1, \mathrm{~N}=135]=5.310, p<.026\right)$; but not with wearing sportswear identifying the characters as a fan. Nonetheless, none of these turned out to be significant at a .001 significance level. Junk food consumption frequency was not observed to be determined by any of the other variables.

\section{Online betting}

Sports betting introduced new functionalities in $34.1 \%$ of the adverts, with some of them claiming that those new functionalities would increase the probability of winning or the control over bets (22.2\%). Although the ease of use of sports betting online platforms was implied in virtually all of the adverts, only $19.3 \%$ explicitly claimed such ease by mentioning words such as "simply", or "easy".

Approximately half of the adverts (46\%) showed characters betting while watching sport (either physically in the stadium or on a screen). It was thought that in-play betting would be more frequent whenever adverts introduced new functionalities $\left(\chi^{2}[1, \mathrm{~N}=135]=4.057, p<.044\right)$, or in general, resources that claimed to enhance the probability of winning $\left(\chi^{2}[1, N=135]=8.438\right.$, $p<.004)$. Similarly, in-play betting was more strongly associated with indicators of sport identification such as the appearance of characters showing satisfaction $\left(\chi^{2}[2, N=135]=28.946\right.$, $p<.001)$, or characters celebrating goals $\left(\chi^{2}[1, \mathrm{~N}=135]=9.109, p<.003\right)$, which were both statistically significant. Those adverts that showed characters betting in-play were also more likely to portray alcohol drinking $\left(\chi^{2}[1, \mathrm{~N}=135]=6.199, p^{<.013}\right)$, albeit this association was not significant.

Mobile betting was the predominant form of betting advertised. Most of the adverts $(92.4 \%)$ that depicted characters betting showed him (and rarely her) doing so through their smartphone. This was the only statistically significant difference found between the Spanish and English samples $\left(\chi^{2}[2, \quad \mathrm{~N}=92]=15.200, \quad p<.001\right)$. English adverts portrayed 68 bets placed by smartphones $(98.5 \%)$, one placed by tablets $(1.4 \%)$, and none by laptops. Spanish adverts also 
showed a majority of bets placed by smartphones (73.9\%), and a minority by tablets (17.3\%), and laptops $(8.6 \%)$.

\section{Wagers placed}

Stakes, odds, potential returns and cashed money greatly varied between adverts. Due to large mean standard deviations, the median was calculated for a better understanding of what constituted a normal representation of values for wagers. The median resulted in a 10 monetary unit stake (pound or Euro), with a minimum wager of $£ / € 5$ and a maximum of $£ / € 50$. The median for potential return was $£ / € 85$, with a minimum return of $£ / € 7.50$ and a maximum of $£ / € 576$. No wager represented resulted in a monetary loss. Only 16 adverts represented bettors actually cashing money from their bets, with a median of $£ / € 67$ (range $£ / € 10-268$ ).

The median for odds visible on device screen was 4.40 decimal odds. The minimum odds showed was 1.5 (1/2 in fractional notation), that is, an event with an expected winning probability of $50 \%$, but on average odds promised a return of investment 7.5 times larger than the invested capital, which, in turn, implied a winning probability of $13 \%$. The riskier bets showed odds that involved returns of 51 times the invested money (implied probability of less than 2\%). No adverts showed on-screen bets in which the implied probability of winning was higher than the probability of losing. It was hypothesized that longer odds would be associated with adverts showing free bets. As the assumption of normal distribution was violated, a nonparametric test (Mann-Whitney $U$ ) was conducted to compare the odds in adverts with free bets versus those without them. However, the results showed no significant difference between the groups $(U=85.500, \mathrm{Z}=-.216, p=.82)$.

\section{Other variables}

Just over one-third of the adverts $(36.3 \%)$ promoted some kind of free bet or refund when signing up as their clients. It was hypothesized that those adverts offering free bets might involve a more impulsive representation of characters (e.g., drinking alcohol). However, drinking alcohol and free bet offers did not show a significant relation $\left(\chi^{2}[1, N=135]=2.803\right.$, $p<.070)$. Over half of the adverts $(59.3 \%)$ were coded as containing comic elements (i.e., humour). Just under one-quarter of the adverts (23\%) had at least one character played by a celebrity (typically a former soccer player).

A minority of adverts included luxurious elements (14.1\%). However, such adverts more frequently contained women in them. Among the 19 adverts identified as portraying luxurious life, eight showed women in them (42\%), above the typical $23 \%$ of adverts depicting women 
at all. This relationship was not statistically significant at a .001 level $\left(\chi^{2}[3, N=135]=9.764\right.$, $p<.017)$. Also, drinking alcohol in non-luxurious adverts occurred $6.6 \%$ of the time, whereas drinking alcohol in luxurious settings was $40 \%$. This difference was statistically significant $\left(\chi^{2}[1, \mathrm{~N}=135]=21.438, p<.001\right)$.

\section{Discussion}

This study explored the social representation of sports betting in Great Britain and Spain by examining bookmakers' advertising narratives. The results indicate that bookmakers reproduce through their advertising representation a number of distinctive and repetitive patterns of betting on sports that, as a whole, conventionalizes betting behaviour, and more specifically, prescribing some betting behaviours while ignoring or minimizing others.

The results showed that betting adverts featuring males were predominant, accounting on average for as much as $96.9 \%$ of the characters in them. Male preponderance in sports betting media representations has been previously noted by Milner (2013). Other gambling advert analyses have also reported findings along such lines. For instance, an average of seven males per commercial, and 84\% of male voiceover in television adverts (McMullan \& Miller, 2008), and $83 \%$ of male actors in lottery radio adverts (McMullan \& Miller, 2009). A number of researchers have noted that sports betting adverts clearly target males, as evidenced by content analysis results from adverts (Deans, Thomas, Daube, Derevensky, et al., 2016), as well as from self-reports from sports bettors in focus groups (Sproston et al., 2015), and individual interviews (Deans et al., 2017; Thomas et al., 2012). The targeting of males reflects data from sports bettors via online questionnaires showing that males are seven times more likely to bet on sports than women (Gassmann, Emrich, \& Pierdzioch, 2017), and that being male (and single) is a risk factor for developing gambling-related problems (Hing, Russell, Vitartas, \& Lamont, 2016).

In contrast, the scarcity of female representations was also observed. Although no previous work had quantified the extent of such absence, some studies have reported that women appeared objectified in as much as $25 \%$ of an Australian sports betting adverts sample (Deans, Thomas, Daube, Derevensky, et al., 2016). This might not come as a surprise considering the (i) conceptualisation of sports betting by some Australian bettors as a 'boy's club' (Deans et al., 2017), (ii) gender stereotypes largely present in betting marketing (Thomas et al., 2015), and (iii) male-centric atmosphere described in an ethnographic study of British sports betting shops (Cassidy, 2014). 
In regard to group betting, the present study departs from existing literature in adding an extra layer of complexity. Studies have noted the role of peers in facilitating sports betting (Deans, Thomas, Daube, \& Derevensky, 2017), with mateship and camaraderie as influencing factors to bet (Thomas et al., 2015), as well as the importance of betting to fit in and share topics of conversation (Deans, Thomas, Daube, Derevensky, et al., 2016). This aligns well with previous literature which asserts that gambling adverts reproduce the idea that gambling with friends is not gambling per se (Korn, Hurson, \& Reynolds, 2005), or that risky behaviours such as drinking alcohol in groups is potentially less harmful (Strate, 1992). However, here the focus was on understanding if the betting action actually happened as a true interaction (e.g., conversation or other signs of mutual awareness) with friends, or if betting with friends was represented by surrounding main characters with people around them with no real interaction. The latter was found to be more accurate. Less than one-quarter of the bettors actually interacted with those around them, and in two-fifths of cases (41\%) bettors did not interact.

This could be a symptom of mobile betting technology, also heavily represented in the sample (92.4\%). Smartphones are individual consumption devices, in which settings correspond to the individuals who own them (e.g., apps, identity verification to access bookmakers' sites, but more importantly, credit card details). In the past, sports fans could pool money to place group bets (Forrest \& Simmons, 2003). Contemporary betting advertising, although at first sight still embedded in those same sport rituals of group betting, necessitates in the end to transform group interaction into consumption, which is by definition individual. This interpretation highlights a probable contradiction in representing sports betting, which has already been observed in sports watching in America, by which bookmakers and sport content broadcasters hold to the illusion of sport consumption as a communal experience when the numbers indicate that the majority of fans watch sports alone (Entertainment and Sports Programming Network, 2010), and perhaps bet on them alone as well. Also, the disparity of spatial and temporal locations where the characters in adverts are shown betting -which offers no clear pattern of representation - testifies to the mobile nature of betting technology and its seamless availability.

In-play betting was depicted in just under half of all the adverts (46\%). New resources and products that claim to enhance winning probability were expected to increase under in-play conditions, but the data analysed provided limited support to this association. Similarly, free bets or money-back guarantees, which are considered by some bettors as 'insurance type of bets' (Deans et al., 2017), and of high utility (Hing, Vitartas, \& Lamont, 2014), were not meaningfully associated with in-play betting. 
Also in relation to in-play betting, it was presumed that watching an emotionally charged media content would increase the probability of seeing simultaneously similarly emotional actions such as those in relation to sport identification (e.g., goal celebrations and showing satisfaction). These associations were observed to work in the predicted direction, although the results were generally only significant at .05 level. This is worth further exploration in the future. In-play betting is one of the fastest growing markets for bookmakers (iGaming Business, 2016), and in Spain it represents over two-thirds of the overall money wagered on sports (Dirección General de Ordenación del Juego [DGOJ], 2017). In-play betting has been found to be more prevalent among problem gamblers (Hing, Russell, et al., 2016), and watching live games (and the integrated gambling adverts on it) while betting affects the way bettors think about their bets, carrying out less planned and more impulsive bets (Lamont et al., 2016). The higher co-occurrence of alcohol and in-play betting found in this study, although statistically non-significant, invites further research, particularly given the sanitisation effects of sport in risky behaviours (Lopez-Gonzalez, Estévez, \& Griffiths, 2017), and the potential interaction of drinking alcohol with impulsive betting.

The representation of how much money should typically be exchanged in a sports wager showed a tendency towards small stake bets (between $£ / € 5$ and $£ / € 10$ ) that were multiplied several times for a great potential return. Staked figures were in accordance with those from studies using real-life data from betting operators, which have reported average bets of $€ 6.40$ from problem gamblers (LaBrie \& Shaffer, 2011). Regarding potential return, research examining UK betting promotions has shown that bookmakers tend to encourage consumers to place money on bets that have greater implied profit margins for the company, emphasizing bets with multiple possible outcomes and large potential returns (Newall, 2015). Similar strategies have also been observed in Australian bookmaker promoting 'exotic' (typically accumulator) and multiple bets (Hing, Sproston, Brook, \& Brading, 2016). This is because bettors are better at calculating simple three-outcome bets (such as the winner of a soccer game), but are more likely to overestimate their probabilities of winning in multiple outcome bets with longer odds, as the calculation becomes increasingly complex (Newall, 2017; Vaughan Williams, 1999). The combination of small stakes, with a low individual impact on the finances of the bettor if lost, and big returns, could help to reduce the perceived danger of bets, and present long-odds bets as great business opportunities with an attractive return of investment. This contrasts to the reality of the odds advertised in the present study, always over the 1.5 threshold, meaning that for every advert it was statistically more likely for bettors to lose than to win their bet. 
Just over one-third of the adverts here (36\%) contained free bets or other kind of refunds. These numbers are significantly lower than the $47 \%$ reported for an Australian sample of sports betting adverts (Hing, Sproston, et al., 2016). Humour was observed in 59\% of the adverts and has been previously proposed as a normalising strategy for gambling behaviours in children (Monaghan, Derevensky, \& Sklar, 2008; Sklar \& Derevensky, 2011), and as an efficient persuasive mechanism (McMullan \& Miller, 2008). Celebrity endorsements, although less predominant than humour in the present sample, have also been interpreted as seeking betting normalisation and social acceptance, either in empirical studies (Derevensky, Sklar, Gupta, \& Messerlian, 2010), advert content analysis (Deans, Thomas, Daube, Derevensky, et al., 2016), focus groups with sports bettors (Hing et al., 2015; Lamont et al., 2016), and interviews with bettors' families (Thomas, 2014). In the present study, luxurious or glamorous representations of betting were much less prevalent (14\%). However, the co-representation of luxury along with alcohol consumption provides preliminary grounds to assess whether the depiction of such association could be detrimental for individuals with either gambling- or drinking-related problems.

This study is not without limitations. The inclusion criteria for the adverts caused the selected sample to be skewed in two directions. First, the combination of British and Spanish adverts in the same sample meant British adverts were overrepresented, as their betting operators produced many more adverts during the analysed period. This fact was disregarded, since only three variables showed differences between countries - betting inside the stadium was more prevalent in the UK, betting with friends more frequent in Spain, but only the differences in laptop and tablet use were statistically significant. However, it is possible that other differences might not have arisen, or may have become statistically significant, with a larger sample size. Second, it is likely that the extraction method via YouTube time stamps have biased the sample towards more recent adverts, under-representing those made in 2014 and 2015. Furthermore, the present study has not explored the differences among bookmakers. Although many variables varied significantly between brands, it was considered that these variations were a consequence of the inclusion criteria, which resulted in a disproportionate prevalence of advertisements from the most popular brands sampled. For the purpose of this study, the authors decided against controlling for such disproportion, considering that this is the way bettors and sport fans consume those advertisements in real life, and learn what a normal betting behaviour is. 


\section{Implications and conclusion}

This study has highlighted a number of repeated patterns of representation that could have a detrimental impact on public health. First, the almost exclusive targeting of male bettors reproduces the traditional stereotypes around gambling behaviour. By aligning betting with masculinity, bettors might feel mirrored in narratives that emphasize self-efficacy and control, while downplaying risk. Additionally, these masculine narratives might resonate those of professional sport, borrowing from sportsmen commonly attributed characteristics such as sensation-seeking (Fortune \& Goodie, 2010). Although the present study solely focused on soccer advertising, the rapid popularisation of extreme and adventure sports (Kupciw \& MacGregor, 2012) might — in the near future — pose a bigger threat when it comes to the sportto-bet transference of risk-taking and recklessness components.

The study also showed preliminary evidence of co-representation between in-play betting and emotionally charged experiences, and less frequently with alcohol consumption. These are particularly relevant in the context of sports, in which national and local sentiments of identity and belonging are intertwined with sport appreciation (Giulianotti, 2002; Lopez-Gonzalez, Guerrero-Sole, \& Haynes, 2014). For live in-play betting, it is plausible for such emotions to escalate in the heat of the game, leading to greater levels of impulsivity, and disinhibition, known factors for problem gambling (McCormick, 1993; Nower \& Blaszczynski, 2006). As opposed to other forms of gambling wherein traits such as impulsivity can only be reinforced within the activity itself (e.g., by modifying structural characteristics of the games such as reducing the average time between spins in roulette), betting procures outside-gambling sporting components of impulsivity that bookmakers can add to the gambling product itself.

Another finding of this study is the hegemonic representation of mobile betting. One of the attributes of mobile phone gambling is its instantaneity (Griffiths, 2010). The increasing availability of ultrafast gambling affordances (e.g., one-click bets) theoretically poses a real threat in terms of impulse control in emotionally charged situations like the ones described in the context of live in-play betting. Furthermore, as observed in the distribution of wagers, the adverts analysed here represented bets with lower expected winnings, and inherent higher risks, catering to the cognitive biases of bettors. All these potentially detrimental characteristics represented (i.e., sensation-seeking, disinhibition, impulsivity, instant betting, and cognitive bias) might not be decisive on their own, but the cumulative effect of their co-representation is difficult to overlook when assessing their influence in determining problem gamblers' and adolescents' betting behaviour. 
Considering the rise of sports betting advertising and marketing that followed the legalisation of online gambling in most European states, media-based social representations may be playing a significant role in communicating to current and future bettors how betting is (or should be) typically carried out, and what a bettor typically looks like. Such betting representations are far from neutral, and they are increasingly important in the context of a newly adopted product - i.e., online betting-, to which consumers are not completely familiarised, and might be more receptive regarding its normative consumption. Policymakers and legislators should be cognizant of the potential effects of betting marketing and advertising, especially when they target vulnerable groups, over-represent or under-represent collectives, and irresponsibly associate betting with sports culture.

\section{References}

Bestman, A., Thomas, S. L., Randle, M., \& Thomas, S. D. M. (2015). Children's implicit recall of junk food, alcohol and gambling sponsorship in Australian sport. BMC Public Health, 15, 1022. http://doi.org/10.1186/s12889-015-2348-3

Binde, P. (2014). Gambling advertising: A critical research review. London: Responsible Gambling Trust.

Cassidy, R. (2014). "A place for men to come and do their thing”: Constructing masculinities in betting shops in London. British Journal of Sociology, 65(1), 170-191.

Davies, R. (2016). Betting firms spent half a billion pounds on TV adverts since 2012. $\begin{array}{llll}\text { Retrieved January } & \text { 5, 2017, from }\end{array}$ https://www.theguardian.com/society/2016/jul/15/betting-firms-spent-half-a-billionpounds-on-tv-adverts-since-2012

Deans, E. G., Thomas, S. L., Daube, M., \& Derevensky, J. (2017). The role of peer influences on the normalisation of sports wagering: A qualitative study of Australian men. Addiction Research \& Theory, 25(2), 103-113.

Deans, E. G., Thomas, S. L., Daube, M., Derevensky, J., \& Gordon, R. (2016). Creating symbolic cultures of consumption: an analysis of the content of sports wagering advertisements in Australia. BMC Public Health, 16(1), 208.

Deans, E. G., Thomas, S. L., Derevensky, J., \& Daube, M. (2017). The influence of marketing on the sports betting attitudes and consumption behaviours of young men: implications for harm reduction and prevention strategies. Harm Reduction Journal, 14(1), 5. 
Derevensky, J., Sklar, A., Gupta, R., \& Messerlian, C. (2010). An empirical study examining the impact of gambling advertisements on adolescent gambling attitudes and behaviors. International Journal of Mental Health and Addiction, 8, 21-34.

Dirección General de Ordenación del Juego [Directorate General for the Regulation of Gambling].]. (2017). Datos del mercado de juego online. Madrid, Spain: Ministerio de Hacienda y Administraciones Públicas.

Entertainment and Sports Programming Network (2010). ESPN top ten list for sport research. Integrated media research report. Las Vegas: Broadcast Education Association Research Symposium.

Forrest, D., \& Simmons, R. (2003). Sport and gambling. Oxford Review of Economic Policy, 19(4), 598-611.

Fortune, E. E., \& Goodie, A. S. (2010). The relationship between pathological gambling and sensation seeking: the role of subscale scores. Journal of Gambling Studies, 26(3), 33146.

Gavriel Fried, B., Teichman, M., \& Rahav, G. (2010). Adolescent gambling: Temperament, sense of coherence and exposure to advertising. Addiction Research \& Theory, 18(5), $586-598$.

Gainsbury, S., King, D. L., Russell, A. M. T., Delfabbro, P., Derevensky, J., \& Hing, N. (2016). Exposure to and engagement with gambling marketing in social media: Reported impacts on moderate-risk and problem gamblers. Psychology of Addictive Behaviors, 30(2), 270276.

Gambling Commission. (2016). Industry Statistics. London: Gambling Commission.

Gassmann, F., Emrich, E., \& Pierdzioch, C. (2017). Who bets on sports? Some further empirical evidence using German data. International Review for the Sociology of Sport, 52(4), 391-410.

Giulianotti, R. (2002). Supporters, Followers, Fans, and Flaneurs: A Taxonomy of Spectator Identities in Football. Journal of Sport \& Social Issues, 26(1), 25-46.

Gordon, R., \& Chapman, M. (2014). Brand community and sports betting in Australia. Victoria, Australia: Victorian Responsible Gambling Foundation.

Griffiths, M. D. (2005). Does gambling advertising contribute to problem gambling? International Journal of Mental Health \& Addiction, 3, 15-25.

Griffiths, M. (2010). Gambling addiction on the Internet. In K. Young, \& C. Nabuco de Andreu (Eds.), Internet Addiction: A Handbook and Guide to Evaluation and Treatment (pp. 91112). New Jersey: John Wiley \& Sons. 
Hanss, D., Mentzoni, R. A., Griffiths, M. D., \& Pallesen, S. (2015). The impact of gambling advertising: Problem gamblers report stronger impacts on involvement, knowledge, and awareness than recreational gamblers. Psychology of Addictive Behaviors, 29(2), 483491.

Hing, N., Lamont, M., Vitartas, P., \& Fink, E. (2015). Sports bettors' responses to sportsembedded gambling promotions: Implications for compulsive consumption. Journal of Business Research, 68, 2057-2066.

Hing, N., Russell, A. M. T., Lamont, M., \& Vitartas, P. (2017). Bet anywhere, anytime: An analysis of internet sports bettors' responses to gambling promotions during sports broadcasts by problem gambling severity. Journal of Gambling Studies. Epub ahead of print. http://doi.org/10.1007/s10899-017-9671-9

Hing, N., Russell, A. M. T., Vitartas, P., \& Lamont, M. (2016). Demographic, behavioural and normative risk factors for gambling problems amongst sports bettors. Journal of Gambling Studies, 32(2), 625-641.

Hing, N., Sproston, K., Brook, K., \& Brading, R. (2017). The structural features of sports and race betting inducements: Issues for harm minimisation and consumer protection. Journal of Gambling Studies, 33(2), 685-704.

Hing, N., Vitartas, P., \& Lamont, M. (2014). Promotion of gambling and live betting odds during televised sport: Influences on gambling participation and problem gambling. Lismore: Centre for Gambling Education and Research.

Hirschman, E. C. (1988). The ideology of consumption: A structural-syntactic analysis of “Dallas” and “ Dynasty ." Journal of Consumer Research, 15(3), 344-59.

Höijer, B. (2011). Social representations theory: A new theory for media research. Nordicom Review, 32(2), 3-16.

iGaming Business (2016). In-play focus 2016. London: Clarion Events Ltd.

Korn, D., Hurson, T., \& Reynolds, J. (2005). Commercial gambling advertising: Possible impact on youth knowledge, attitudes, beliefs, and behavioural intentions. Guelph: Ontario Problem Gambling Research Centre.

Krippendorff, K. (2013). Content Analysis: An introduction to its methodology. Thousand Oaks, CA: Sage.

Kupciw, D., \& MacGregor, A. (2012). High-risk sport research. Sport \& Exercise Scientist, 31, 28-29. I checked the pdf of this online and it's vol 31

LaBrie, R., \& Shaffer, H. J. (2011). Identifying behavioral markers of disordered Internet sports gambling. Addiction Research \& Theory, 19(1), 56-65. 
Lamont, M., Hing, N., \& Gainsbury, S. (2011). Gambling on sport sponsorship: A conceptual framework for research and regulatory review. Sport Management Review, 14(3), 246257.

Lamont, M., Hing, N., \& Vitartas, P. (2016). Affective response to gambling promotions during televised sport: A qualitative analysis. Sport Management Review, 19(3), 319-331.

Lindsay, S., Thomas, S., Lewis, S., Westberg, K., Moodie, R., \& Jones, S. (2013). Eat, drink and gamble: marketing messages about "risky" products in an Australian major sporting series. BMC Public Health, 13(1), 719.

Lopez-Gonzalez, H., Guerrero-Sole, F., \& Haynes, R. (2014). Manufacturing conflict narratives in Real Madrid versus Barcelona football matches. International Review for the Sociology of Sport, 49(6), 688-706.

Lopez-Gonzalez, H., Estévez, A., \& Griffiths, M. D. (2017). Marketing and advertising online sports betting: A problem gambling perspective. Journal of Sport \& Social Issues, 41(3), $256-272$.

Lopez-Gonzalez, H., \& Griffiths, M. D. (2016). Understanding the convergence of online sports betting markets. International Review for the Sociology of Sport. Epub ahead of print. http://doi.org/doi:10.1177/1012690216680602

Lopez-Gonzalez, H., \& Tulloch, C. D. (2015). Enhancing media sport consumption: Online gambling in European football. Media International Australia, 155, 130-139.

Lund, I. (2011). Irrational beliefs revisited: Exploring the role of gambling preferences in the development of misconceptions in gamblers. Addiction Research \& Theory, 19(1), 40-46.

McCormick, R. A. (1993). Disinhibition and negative affectivity in substance abusers with and without a gambling problem. Addictive Behaviors, 18(3), 331-336.

McMullan, J. L., \& Miller, D. (2008). All in! The commercial advertising of offshore gambling on television. Journal of Gambling Issues, 22, 230-251.

McMullan, J. L., \& Miller, D. (2009). Wins, winning and winners: The commercial advertising of lottery gambling. Journal of Gambling Studies, 25, 273-295.

Mela, C. F., Gupta, S., \& Lehmann, D. R. (1997). The long-term impact of promotion and advertising on consumer brand choice. Journal of Marketing Research, 34(2), 248-261.

Milner, L., Hing, N., Vitartas, P., \& Lamont, M. (2013). Embedded gambling promotion in Australian football broadcasts: An exploratory study. Communication Politics \& Culture, 46(2), 177-198.

Monaghan, S., Derevensky, J., \& Sklar, A. (2008). Impact of gambling advertisements and marketing on children and adolescents: Policy recommendations to minimise harm. 
Journal of Gambling Issues, 22, 252-274.

Moscovici, S. (1961). La psychanalyse, son image et son public. Paris: Presses universitaires de France.

Moscovici, S. (2000). The phenomenon of social representations. In G. Duveen (Ed.), Social representations: Explorations in social psychology (pp. 18-77). Cambridge, UK: Polity Press.

Newall, P. W. S. (2015). How bookies make your money. Judgment and Decision Making, $10(3), 225-231$.

Newall, P. W. S. (2017). Behavioral complexity of British gambling advertising. Addiction Research \& Theory. Epub ahead of print. http://doi.org/10.1080/16066359.2017.1287901

Nower, L., \& Blaszczynski, A. (2006). Impulsivity and pathological gambling: A descriptive model. International Gambling Studies, 6(1), 61-75.

Parke, A., \& Griffiths, M. (2012). Beyond illusion of control: An interpretative phenomenological analysis of gambling in the context of information technology. Addiction Research \& Theory, 20(3), 250-260.

Parke, A., Harris, A., Parke, J., Rigbye, J., \& Blaszczynski, A. (2014). Responsible marketing and advertising in gambling: A critical review. Journal of Gambling Business and Economics, 8(3), 21-35.

Pitt, H., Thomas, S., Bestman, A., Stoneham, M., \& Daube, M. (2016). "It's just everywhere!" Children and parents discuss the marketing of sports betting in Australia. Australian and New Zealand Journal of Public Health, 40(5), 480-486.

Reid, R. L. (1986). The psychology of the near miss. Journal of Gambling Behavior, 2(1), 3239.

Reith, G., \& Dobbie, F. (2011). Beginning gambling: The role of social networks and environment. Addiction Research \& Theory, 19(6), 483-493.

Rimal, R. N., \& Real, K. (2003). Understanding the influence of perceived norms on behaviors. Communication Theory, 13(2), 184-203.

Scott, W. (1995). Institutions and organizations. Thousand Oaks, CA: Sage Publications.

Scott, W. (2014). Institutions and organizations: Ideas and interests (4th ed.). Thousand Oaks, CA: Sage Publications.

Shead, N. W., Walsh, K., Taylor, A., Derevensky, J. L., \& Gupta, R. (2011). Youth gambling prevention: Can public service announcements featuring celebrity spokespersons be effective? International Journal of Mental Health and Addiction, 9(2), 165-179.

Sklar, A., \& Derevensky, J. L. (2011). Way to play: Analyzing gambling ads for their appeal 
to underage youth. Canadian Journal of Communication, 35(4), 533-554.

Sproston, K., Hanley, C., Brook, K., Hing, N., \& Gainsbury, S. (2015). Marketing of sports betting and racing. Melbourne: Gambling Research Australia.

Strate, L. (1992). Beer commercials: a manual on masculinity. In Craig, S. (Ed.), Men, masculinity and the media (pp. 78-92). London: Sage Publications.

Thomas, S. (2014). Parents and adolescents discuss gambling advertising: A qualitative study. Melbourne: Victorian Responsible Gambling Foundation.

Thomas, S., Bestman, A., Pitt, H., Deans, E., Randle, M., Stoneham, M., \& Daube, M. (2015). The marketing of wagering on social media: An analysis of promotional content on YouTube, Twitter and Facebook. Victoria, Australia: Victorian Responsible Gambling Foundation.

Thomas, S., Lewis, S., McLeod, C., \& Haycock, J. (2012). "They are working every angle”. A qualitative study of Australian adults' attitudes towards, and interactions with, gambling industry marketing strategies. International Gambling Studies, 12(1), 111-127.

Van Rompuy, B., \& Asser Institute. (2015). The odds of match fixing facts \& figures on the integrity risk of certain sports bets. Brussels: Asser International Sport Law Centre.

Vaughan Williams, L. (1999). Information efficiency in betting markets: a survey. Bulletin of Economic Research, 51(1), 1-39.

Woolley, R. (2003). Mapping internet gambling: Emerging modes of online participation in wagering and sports betting. International Gambling Studies, 3(1), 3-21. 
Table 1. List of sports betting behaviour items and their descriptive statistics

\section{Items (abridged definition)}

\section{General Information}

Brand name

Advert length

Language

Year

\section{Descriptive statistics}

$\mathrm{n} / \mathrm{a}$

$\mathrm{M}=31.05$ seconds; $\mathrm{SD}=9.02$; Range 12-60

English $(\mathrm{n}=101$ [74.8\%], Spanish $(\mathrm{n}=34$ [25.2\%])

$2014(\mathrm{n}=15[11.1 \%]) ; 2015(\mathrm{n}=28$

[20.7\%]); $2016(\mathrm{n}=92[68.2 \%])$

\section{Characters and situations}

How many characters appear performing an action?

How many men appear performing an action?

How many women appear performing an action?

Is there a character shown betting?

If the character bets with others, with whom?

What is the space in which the action happens for the longest period of time?

If the answer is house, which is the space in which the main or the longest action happens?

What time of the day is the action set?
$\mathrm{M}=2.31 ; \mathrm{SD}=0.98$

None $(\mathrm{n}=9$ [6.7\%]); $1(\mathrm{n}=24[17.8 \%]) ; 2$ $(\mathrm{n}=18[13.3 \%]) ; 3$ or more $(\mathrm{n}=84[62.2 \%])$

$\mathrm{M}=2.24 ; \mathrm{SD}=1.02$.

None $(\mathrm{n}=10$ [7.4\%]); $1(\mathrm{n}=28$ [20.7\%]); 2 $(\mathrm{n}=17$ [12.6\%]); 3 or more $(\mathrm{n}=80$ [59.3\%])

$\mathrm{M}=0.3 ; \mathrm{SD}=0.62$.

None $(\mathrm{n}=104[77 \%]) ; 1(\mathrm{n}=25$ [18.5\%]); 2 $(n=3[2.2 \%]) ; 3$ or more $(n=3[2.2 \%])$

No $(\mathrm{n}=46[34.1 \%])$; Yes, alone $(\mathrm{n}=56$ [41.5\%]); Yes, with others $(n=33$ [24.4\%])

Friends $(n=31[93.9 \%])$; Partner $(n=1$ [3\%]); Undetermined ( $\mathrm{n}=1[3 \%])$

House ( $\mathrm{n}=28$ [20.7\%]); Pub or restaurant $(\mathrm{n}=17$ [12.6\%]); Stadium ( $\mathrm{n}=29$ [21.5\%]); Other indoor $(\mathrm{n}=17$ [12.6\%]); Outdoor $(\mathrm{n}=26$ [19.3\%]); Undetermined $(\mathrm{n}=18$ [13.3\%])

Living room $(\mathrm{n}=22$ [78.5\%]); Kitchen $(\mathrm{n}=2$ [7.1\%]); Other $(\mathrm{n}=4$ [14.2\%])

Daytime ( $\mathrm{n}=69$ [51.1\%]); Nigh-time $(\mathrm{n}=29$ [21.5\%]); Undetermined $(\mathrm{n}=37$ [27.4\%])

No $(\mathrm{n}=20$ [88.9\%]); Yes $(\mathrm{n}=14$ [10.4\%]); Undetermined $(\mathrm{n}=1[0.7 \%])$

No $(n=100[74.1 \%])$; Yes $(n=35$ [25.9\%]) point celebrate a goal?

Does the main character(s) show satisfaction from what it is implied to be the outcome of a bet or of a game?

No $(\mathrm{n}=97$ [71.1\%]); Yes $(\mathrm{n}=35$ [25.9\%]); Undetermined $(n=3[2.2 \%])$

No $(n=113[83.7 \%])$; Yes $(n=22[16.3 \%])$

Does the advert show or imply that the characters have a sentimental identification with the team, nation, or athlete they are betting? 
Does the advert show characters betting in-play?

Does the advert introduce a new functionality that alters the betting action?

Does the advert present a resource that is claimed to enhance the probability of winning a bet or the control over the bets?

Is the ease of platform use or ease of platform access explicitly expressed in the advert?

Among those adverts that show a character betting, what device is used to bet?

\section{Wager placement}

If a bet is visible, what is the stake shown on the screen of the device? ${ }^{1}$

If a bet is visible, what are the odds shown on the screen of the device? $?^{2}$

If a bet is visible, what is the potential return shown on the screen of the device? ${ }^{1}$

If a bet is visible, what is the actual money pocketed as shown on the screen of the device? ${ }^{1}$

\author{
No $(\mathrm{n}=72[53.3 \%])$; Yes $(\mathrm{n}=63$ [46.7\%]) \\ No $(n=89$ [65.9\%]); Yes $(n=46$ [34.1\%]) \\ No $(n=105[77.8 \%])$; Yes $(n=30[22.2 \%])$ \\ No $(\mathrm{n}=109[80.7 \%]) ;$ Yes $(\mathrm{n}=26$ [19.3\%]) \\ Mobile phone ( $\mathrm{n}=85$ [92.4\%]); Tablet $(\mathrm{n}=5$ \\ [5.4\%]) ; Laptop ( $\mathrm{n}=2$ [2.2\%])
}

$\mathrm{N}=31 . \mathrm{M}=15.16 ; \mathrm{SD}=10.9 ; \mathrm{Mdn}=10 ;$ Range (5-50)

$\mathrm{N}=28 . \mathrm{M}=7.51 ; \mathrm{SD}=9.59 ; \mathrm{Mdn}=4.40$;

Range (1.5-51)

$\mathrm{N}=28 . \mathrm{M}=132.64 ; \mathrm{SD}=150.89 ; \mathrm{Mdn}=85$;

Range (7.5-576)

$\mathrm{N}=16 . \mathrm{M}=83.38 ; \mathrm{SD}=70.66 ; \mathrm{Mdn}=67$;

Range (10-268)

\section{Other risky behaviour}

Are any of the characters in the advert consuming alcohol, or No ( $\mathrm{n}=105$ [77.8\%]); Yes ( $\mathrm{n}=30$ [22.2\%]) alcoholic drinks are displayed?

Are any of the characters in the advert consuming junk food, $\quad$ No ( $\mathrm{n}=99$ [73.3\%]); Yes ( $\mathrm{n}=36$ [26.7\%]) or junk food is displayed?

\section{Other variables identified in the literature}

Does the advert include components of luxury, or glamour?

No $(\mathrm{n}=116[85.9 \%]) ;$ Yes $(\mathrm{n}=19[14.1 \%])$

Does the advert offer free bets (e.g., free money or money No $(\mathrm{n}=86[63.7 \%])$; Yes $(\mathrm{n}=49[36.3 \%])$ back, improved odds, or allows bets from accumulators to be forgiven)?

Are humour components in the advert?

No $(\mathrm{n}=55[40.7 \%]) ;$ Yes $(\mathrm{n}=80[59.3 \%])$

Does the advert include a celebrity?

No $(n=104[77 \%])$; Yes $(n=31[23 \%])$

Notes: ${ }^{1}$ Results show monetary units $(1$ Great British Pound $=1$ Euro $) .{ }^{2}$ Decimal odds. 